\title{
Establishment of System of Bridging Programs of Accounting between Secondary and Higher Vocational Education
}

\author{
XuanJun Chen ${ }^{1, \mathrm{a}}$ and $\mathrm{Han} \mathrm{He}^{2, \mathrm{~b}^{*}}$ \\ ${ }^{1}$ Department of Construction Management and Real Estate, Chongqing Jianzhu College, \\ Chongqing Municipality 400070; \\ ${ }^{2}$ Rongzhi College of Chongqing Technology and Business University, Chongqing, 401320) \\ a535023045@qq.com; ${ }^{b} 923211211 @ q q . c o m$ \\ *The corresponding author
}

\begin{abstract}
Bridging Program is the core and key of secondary and higher vocational education. To achieve the system of bridging program between secondary and higher accounting education, we should focus on vocational competence and design a course system of the integration of secondary and higher vocational education. This essay, based on analysis of China's models of bridging between secondary and higher vocational education, analyzes the problems of accounting bridging programs between secondary and higher vocational education as well as causes of these problems, putting forward the establishment of systems, with the focus on vocational competence, of bridging programs of accounting between secondary and higher vocational education.
\end{abstract}

Keywords: Accounting major; Vocational ability; Connecting secondary and higher vocational education; Curriculum system; Vocational education

\section{会计专业中高职衔接课程体系的构建}

陈宣君 ${ }^{1, \mathrm{a}}$ ，贺晗 $2, \mathrm{~b}, *$

(1. 重庆建筑工程职业学院、建设管理与房地产系, 重庆市400070；2. 重庆工商大学融智学院, 重庆市 401320; * 通讯作者)

摘要: 课程衔接是中高职衔接的核心和关键点, 要实现会计专业中高职衔接课程体系就应该以职业能力为核心设计中、 高职一体化的课程体系。本文在分析我国中高职教育衔接模式基础上, 针对中高职会计专业课程衔接存在的问题及原因进行 分析, 提出构建以职业能力为核心的会计专业中高职衔接课程体系。

关键词: 会计专业; 职业能力; 中高职衔接; 课程体系;职业教育

中图分类号: G712 文献标识码: A

引言

中高职衔接是建设现代职业教育体系的重要内容，也是推动我国职业教育持续健康发展的关键。国务 院《关于加快发展现代职业教育的决定》明确指出：“推进专业设置、专业课程内容与职业标准相衔接, 推进中等和高等职业教育培养目标、专业设置、教学过程等方面的衔接, 形成对接紧密、特色鲜明、动态 调整的职业教育课程体系”。但长期以来, 我国中等职业教育与高等职业教育的课程体系不能有效衔接, 两者各自发展, 产生了课程内容重复等问题, 制约了中高职教育的全面衔接。因此, 研究会计专业中高职 课程体系衔接的问题具有重要的现实意义。

\section{1 我国中高职教育衔接的模式}

近年来，我国职业教育得到了快速发展，探索出多种中高职衔接模式，主要有三种: 


\section{1 对口招生模式}

该模式是中职生毕业后参加单独组织的高职招生考试, 通过考试则可以进入高职院校学习。中职毕业 生可以自主选择专业对口的高职院校。

\section{2 分段贯通模式}

该模式是高职院校与中职院校共同办学，由中等职业学校招收初中毕业生学习三年或四年，经过高职 院校选拨进入高职院校再学习两年或三年，最终颁发大专文凭。

\section{3 五年一贯制模式}

该模式是高职院校以培养专科层次技能型人才为目标，招收应届初中毕业生，进入高职院校学习。学 制五年，中间只参加转段考试。

研究发现, 不同的衔接模式各有特点, 不同的衔接模式的关键问题均为课程的衔接。课程衔接是中高 职衔接的实质与核心问题，是实现中高等职业教育持续、协调发展的关键。实现中高职课程衔接的关键则 在于要按照职业能力的要求构建课程体系, 体现职业教育特色, 实现中高职教育有效衔接。

\section{2 会计专业中高职课程衔接存在的问题}

目前，我国会计专业中、高职课程衔接存在的问题主要有：

\section{1 课程目标定位不明确}

由于我国高职多数是由中职院校升格而来，因此中职院校和高职院校培养目标高度相似，缺乏清晰的 层次定位, 无法显示两者的发展关系, 进而导致中、高职院校课程目标定位不明确, 相互之间缺乏衔接。

\section{2 专业课程设置、教学内容交叉重复}

由于我国中职教育与高职教育各自独立办学, 彼此缺少必要的协作, 加上高职院校人才培养方案基本 按普高毕业生设计, 没有统一的中高职衔接的课程标准, 导致中职开设的课程大多都在高职阶段重新开设, 教学内容重复, 甚至有的课程采用的教材都为同一版本。

\section{3 文化基础课不衔接}

中职学生由于未经过高中阶段的文化课程学习, 文化基础薄弱, 而高职院校文化基础课程均按对普通 高中毕业生的要求开设, 对文化基础课要求比较高, 导致中职生源学生普遍感觉高职院校文化基础课程过 难, 学习积极性降低, 不利于学生未来的发展。

\section{3 构建“一核心、二结合、三阶段、四模块”的中高职衔接课程体系}

\section{1 构建中高职会计专业职业能力培养体系}

在中高职会计专业课程体系衔接的过程中，首先要根据市场需求确定培养目标。培养目标的不同导致 课程目标、课程内容等方面不同。中职培养的是掌握基本的专业理论知识和技能或一般技能的人才，高职 培养高级技能型人才，要求学生具有更精湛的技术素养，掌握的专业理论知识更宽厚。

目前会计专业中职学生的就业岗位主要有中小企业收银、出纳、办税员以及小企业会计核算等; 高职 会计专业毕业生主要就业岗位是各类企事业单位的会计核算、税务核算、审计稽核、成本管理、会计管理 等。通过对中职与高职的就业岗位的调研，分析各自的工作任务及应具备的职业能力。如图 1 所示。 


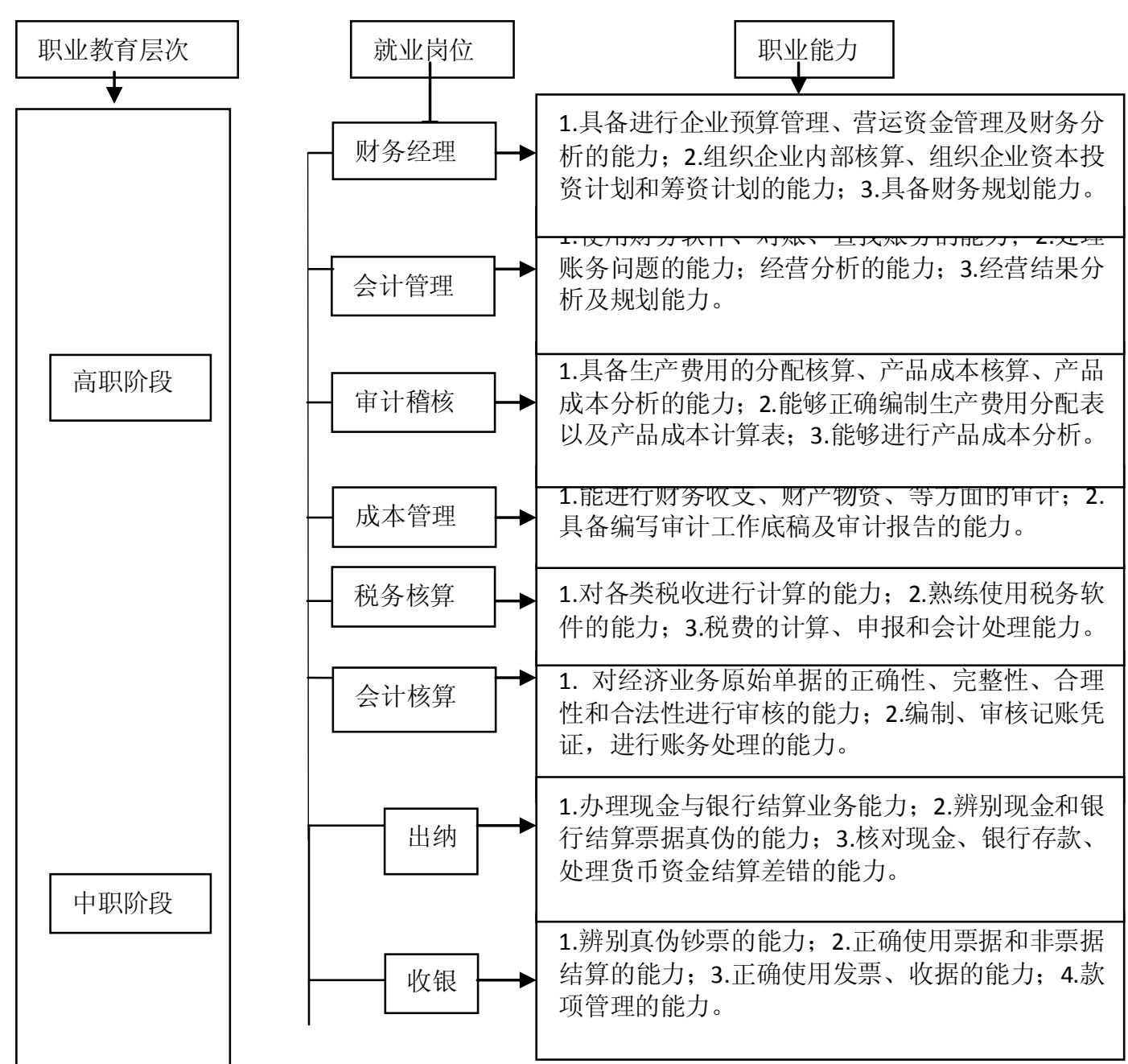

图 1 会计专业职业能力体系分析图

\section{2 构建会计专业 “1234” 中高职衔接课程体系}

通过对会计岗位工作过程的调研与分析, 用行业标准引导职业教育标准, 将典型工作任务转换为学习 领域, 进而构建出会计专业“一核心、二结合、三阶段、四模块”的中高职衔接课程体系。一核心是指以职 业能力为核心; 二结合是指课程结构与就业岗位相结合、教学标准与职业标准相结合; 三阶段是指将课程 分为中职课程阶段、中高职衔接课程阶段和高职课程阶段; 四模块是指将课程设置为职业素养课程模块、 职业基础课程模块、职业技能课程模块、职业拓展课程模块四个课程模块。如表 1 所示。 
表 1 会计专业“1234”中高职衔接课程体系

\begin{tabular}{cccc}
\hline & 一核心 & & 二结合 \\
\hline 职业能力为核心 & 课程结构与就业岗位结合 & 教学标准与职业标准结合 \\
\hline & 三阶段 & & 四模块 \\
\hline 中职课 & 中高职衔接 & 高职课 & 职业素养课程模块、职业基础课程模块、职业技能课 \\
程阶段 & 课程阶段 & 程阶段 & 程模块、职业拓展课程模块 \\
& & & \\
\hline
\end{tabular}

职业能力包含“基础工作能力”、“职业基本能力”、“职业岗位能力”、“职业拓展能力”四个方面, 以职 业能力为主线构建中高职会计专业衔接课程体系。如图 2 所示。

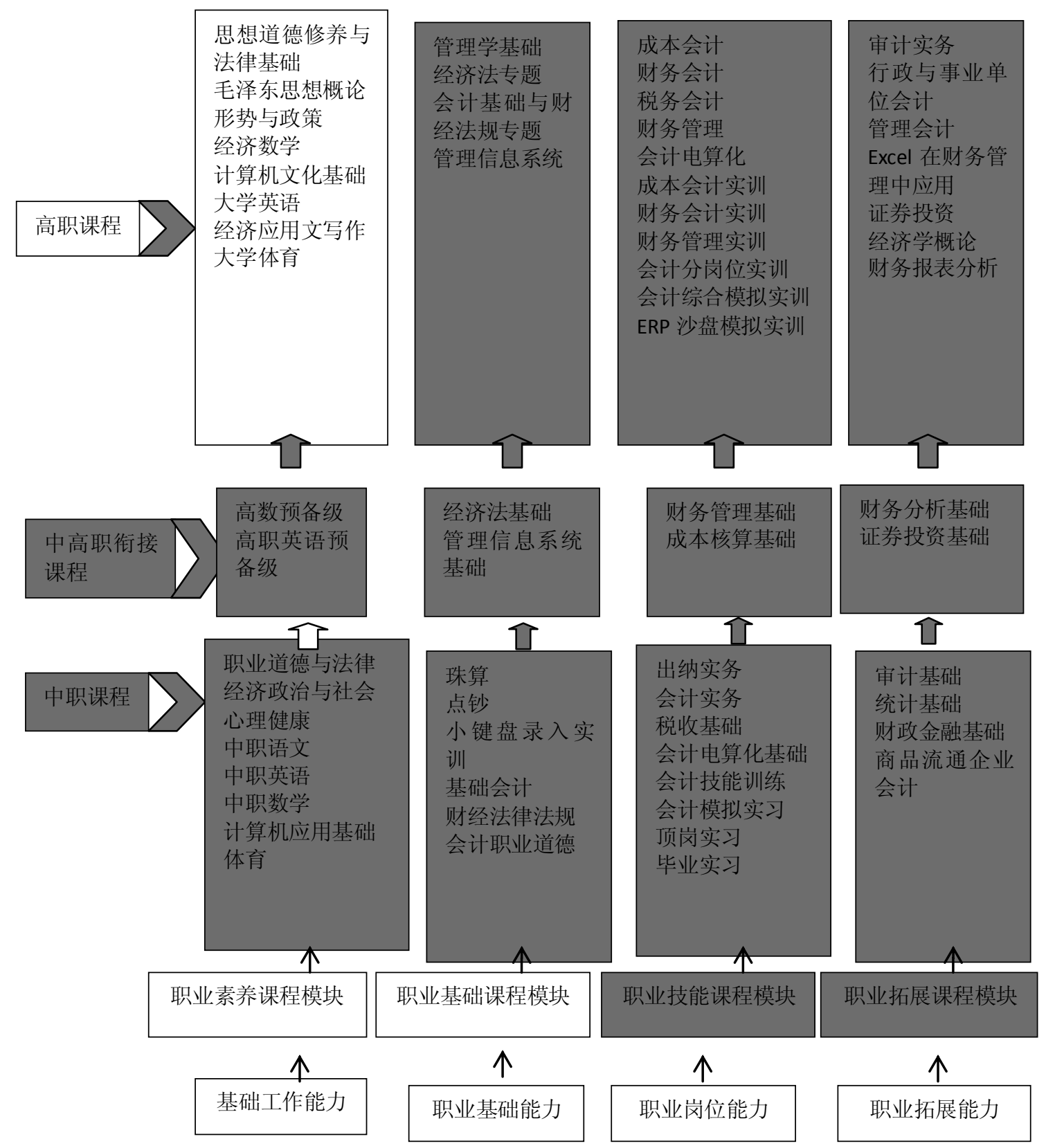

图 2 职业能力-课程体系对位图 


\section{5 会计专业中高职衔接课程体系的实施}

\section{1 以课程标准建设为依托完善课程体系}

开发会计专业中高职一体化课程标准是建设中高职衔接课程体系的重要内容。课程标准是进行教学以 及指导教材开发的依据, 应由省级教育行政部门牵头, 行业教学指导委员会统筹, 组建中职与高职院校教 师、行业企业专家等人员共同开发中高职一体化的课程标准, 作为教学单位的指导性文件。中高职一体化 课程标准, 避免了中高职衔接中课程出现的重复、断档等问题, 将有效实现会计专业中高职课程体系的衔 接。

\section{2 以教材建设为支撑加强课程体系建设}

中高职课程体系衔接依赖于教学内容的衔接, 而教学内容的衔接又依赖于教材的衔接。目前会计专业 中职教材或高职教材都自成体系, 目标不一致、内容不衔接。因此, 会计专业中高职一体化教材的建设成 为加强会计专业中高职衔接课程体系建设的关键。中职和高职教材应合理规划, 充分衔接, 应由中、高职 院校合作共同开发教材，教材内容与课程相对应，避免内容重复，体现中高职教育的连续性。

\section{3 以学分制管理为抓手推进课程体系建设}

建立以学分制为基础的学历职业教育, 建立跨专业、跨学校的中高职一体化学分认证体系, 将学历考 试与职业资格考试以学分进行等值转换, 打通会计专业中高职课程体系衔接中的障碍, 实现学历证书与职 业资格证书对接，职业教育与终身教育对接。对于学生中职阶段选修合格的高职课程，或已取得相应的职 业资格证书，高职阶段计入相应学分，实现中高职教育衔接。

\section{6 结语}

综上所述, 本文以会计专业为例, 构建以职业能力为核心的中高职衔接课程体系, 减少中高职两个层 次在课程设置、课程教学内容等方面的重复, 实现中高职教育有效衔接。中等职业教育要作为基础来发展 高等职业教育, 高等职业教育要充分发挥其引领作用, 带动中等职业教育的发展。构建中高职一体化的课 程体系, 既是推进中等职业教育与高等职业教育协调发展, 实现中高职衔接的有效途径, 也是构建现代职 业教育体系，实现我国职业教育发展的迫切需求。

\section{7 致谢}

本文系重庆市教育科学 “十二五” 规划 2015 年度专项课题 “基于职业能力的中高职课程体系衔接研 究一以会计专业为例” 的研究成果之一。(项目主持人：陈宣君, 项目编号：2015-ZJ-023)

\section{参考文献:}

１1］国务院．国务院关于加快发展现代职业教育的决定 [Z]．国发 [2014］19 号

[2] 荀莉. 中高职课程衔接研究现状综述 $[J]$. 职教论坛, 2012（13）：47-52

[3] 徐国庆, 石伟平. 中高职衔接的课程论研究 [J]．教育研究，2012（5)：69-73

[4] 朱学梅. 我国中职与高职衔接研究述评 $[J]$. 职业技术教育, 2011（7)：24-27

[5] 王文毅. 中高职衔接会计专业课程结构一体化设计研究 [J]。哈尔滨职业技术学院学报, 2015（4)：25-27

[6] 高蓉. 中高职会计专业课程体系衔接的研究 [J]. 商业会计, 2015（12)：123-126

[7] 徐国庆. 职业教育课程论 [M].上海: 华东师范大学出版社, 2008 .

[8］赵晓洁．基于职业能力培养的会计专业课程体系的构建 [J]．教育与职业，2015（12）。101-103

[9] 柳燕君. 构建 “能力递进、纵横拓展、模块化设置” 的中高职课程衔接模式 [J]. 中国职业技术教育，2012（17）: 
[10］姜大源．关于职业教育课程体系的思考[J]．中国职业技术教育，2003（5)：37-39

[11] 李乐．中高职课程体系的衔接——以会计专业为例 [J]。湖北广播电视大学学报, 2014（8)：22-23.

\section{References:}

[1] The State Department. Decision of the State Council on Accelerating Development of Modern Vocational Education [Z].GF [2014] No.19

[2] Xun Li. Survey of Research Situation in High Vocational Courses [J].Vocational \& Technical Education Forum,2012(13):47-52

[3] Xu Guoqing, Shi Weiping. Study on Curriculum Theory of Cohesion in Higher Vocational Education [J].Educational Studies,2012(5):69-73

[4] Zhu Xuemei. Review of Convergence Study in Secondary Vocational and Higher Vocational Education in China [J].Vocational and Technical Education,2011(7):24-27

[5] Wang Wenyi. Research on Integrated Design of Accounting Curriculum Structure to Connect Secondary Vocational and Higher Vocational Education [J].Journal of Harbin Institute of Vocational Technology,2015(4):25-27

[6] Gao Rong. Research on Convergence in Specialty Curriculum System of Accounting in Secondary Vocational and Higher Vocational Education [J].Commercial Accounting,2015(12):123-126

[7] $\mathrm{Xu}$ Guoqing. On Curriculum Theory of Vocational Education [M].Shanghai: East China Normal University Press, 2008.

[8] Zhao Xiaojie. Construction of Course System for Accounting Major Based on Professional Ability Cultivation [J].Education and Vocation,2015(12).101-103

[9] Liu Yanjun. Build Courses Linking Model in Higher Vocational Education of "Progressive Ability, Freely Development, Modular Set" [J].Chinese Vocational and Technical Education,2012(17):56-60

[10] Jiang Dayuan. Thoughts on Curriculum System of Vocational Education [J].Chinese Vocational and Technical Education,2003(5):37-39

[11] Li Le. Convergence of Higher Vocational Curriculum System-A Case Study of Accounting Professional [J].Journal of Hubei Radio \& Television University, 2014(8):22-23.

[12] RalPh W. Tyler. Basic PrinciPles of Curriculum and Instruction [M]. London: The University of Chicago Press.Ltd.1969.

[13] Mantz Yorke. Employability in the Undergraduate Curriculum: some student perspectives [J]. European Journal of Education, Vol.39, No.4, 2004:409-427

[14] Schubert, W.H, Curriculum: Perspective, Paradigm and Possibility, New York: Macmillan Publishing Company, 1986: 190-195

[15] Mohd Yusof Husain,Seri Bunian Mokhtar, Abdul Aziz Ahmad, Ramlee Mustapha. Importance of Employability Skills from Employee' Perspective [J]. Procedia Social and Behavioral Sciences , 2010,7(7): 430-438 